\title{
Presence of Toxocara spp. in Domestic Cats in the State of Mexico
}

\author{
Lucila Marilú Rodríguez Gallegos', Camilo Romero Núñez², Linda Guiliana Bautista Gómez², \\ José Simón Martínez Castañeda ${ }^{3} \&$ Rafael Heredia Cardenas ${ }^{4}$
}

\begin{abstract}
Background: Toxocara spp. is a gastrointestinal nematode with cosmopolitan distribution and is the most common parasite in domestic cats, which can deposit fertilized eggs in the environment with feces. Egg maturation starts in the soil, concluding two to three weeks after cat defecation, but eggs can remain viable in the soil for years and spread onto vegetables and into water. Infection of cats and paratenic hosts (among them humans) occurs through ingestion of infected eggs from the environment, through ingestion of paratenic hosts and, in puppies, through milk from infected mothers. The objective of the present study was to evaluate the presence of Toxocara spp. in domestic cats.

Materials Methods \& Results: In this study, 229 fecal samples from domestic cats were collected in the state of Mexico, Mexico. All of cats had an owner, and fresh feline feces were collected in previously labeled sterile bottles. Coproparasitological examinations were performed on these samples using a flotation technique with sodium hydroxide $(\mathrm{NaOH})$ and sodium nitrate (NaNO3), Toxocara spp. eggs were identified under the microscope, in accordance with the morphological descriptions. The data were analyzed by means of Fisher's exact test in order to compare the presence of Toxocara eggs according to cat age and sex. The chi-square test was used to determine associations between variables and odds ratios (OR) were calculated to determine the risk factors. Presence of Toxocara spp. eggs was identified in 42\% (96/229) of the cats, of which $23 \%$ were males and $19 \%$ females. We did find an association between cats under the age of six months $(P$ $=0.01)$ and the presence of Toxocara spp. eggs, and therefore age was determined to be a risk factor $(\mathrm{OR}=1.69)$ for the presence of Toxocara spp. eggs in feces, cats over one year old showed a statistically significant association $(P=0.02)$ with the presence of parasite eggs in feces. The presence of Toxocara spp. was found to be a risk factor $(\mathrm{OR}=1.57)$ among male cats aged less than 6 months, while among female cats a statistically significant association was found $(P=0.03)$ for the presence of Toxocara spp. Meanwhile, comparing positive cats of both sexes with age, a statistically significant difference $(P=0.02)$ was found regarding cats over one year old.

Discussion: It were identified Toxocara spp. eggs in $42 \%$ of the feces of domestic cats from the state of Mexico. These results are similar to those reported by other studies in Mexico City, they also reported that there was a larger number of infected cats under one year of age and that males had higher infection rates. Comparison of both sexes with age showed a statistically significant association $(P=0.01)$ between cats under six months old and the presence of Toxocara eggs in feces. This age was also considered to be a risk factor $(\mathrm{OR}=1.69)$ for parasite eggs in feces, during the first months of life, the larvae migrate and finish their cycle, but when the cat has reached its mature stage, the larvae may become entrenched and avoid finishing their life cycle. Male sex was identified as a risk factor for the presence of Toxocara spp. The prevalence of Toxocara spp. in domestic cats in the state of Mexico is high, and represents a potential risk of human toxocariasis. From the results found, it can be considered that cats are a major source of dissemination of environmental pollution and Toxocara spp.
\end{abstract}

Keywords: Toxocara, cats, zoonosis, risk factor. 


\section{INTRODUCTION}

Pets play an important role in welfare and human health in different countries [12,18]. Dogs and cats are the domestic animals that are most preferred, even though they present risks as hosts and transmitters of zoonotic diseases, including those caused by parasites [19]. Toxocara cati is the most common parasite in domestic cats [10], although cats can also host other species such as Toxocara canis [14], Toxocara malaysiensis [31] and other nematodes like Toxascaris leonina [15], which can end their life cycle and deposit fertilized eggs in the environment. All of these have the capacity to infect other mammals, including humans [22]. Toxocara spp. females can oviposit up to 200,000 eggs a day, with up to 200 grams of eggs in one gram of feces. Egg maturation starts in the soil, concluding two to three weeks after cat defecation [29,9], but eggs can remain viable in the soil for years and spread onto vegetables and into water [3]. Infection of cats and paratenic hosts (among them humans) occurs through ingestion of infected eggs from the environment, through ingestion of paratenic hosts and, in puppies, through milk from infected mothers [2].

Domestic cats are considered to be one of the most efficient parasite disseminators, because of their habit of roaming outside the home, entering distant spaces and defecating in them [1]. In humans, infection with Toxocara spp. is known as toxocariasis, and this disease can develop as an important series of clinical manifestations that can be classified as follows: visceral larvae, ocular larva migrans, eosinophilic meningitis, covert toxocariasis and neurotoxocariasis [6]. For this reason, the objective of the present study was to evaluate the presence of Toxocara spp. in domestic cats in the state of Mexico.

\section{MATERIALS AND METHODS}

The present study was based on 229 domestic cats in the state of Mexico, comprising 109 males and 120 females of various ages, which were classified as under six months old, six months to one year old and over one year old. All of these cats had an owner, and fresh feline feces were collected in previously labeled sterile bottles and stored at $4^{\circ} \mathrm{C}$ until processed. The feces were processed by means of a coproparasitological method for identifying Toxocara spp. eggs, using the flotation technique as described by Mizgajska [20], with some modifications to the procedure. Less than 5 grams of feces were taken and put in a beaker with 60 $\mathrm{ml}$ of $5 \%$ sodium hydroxide $(\mathrm{NaOH})$. This was then mixed and put into a test tube and centrifuged at 800 $\mathrm{x} g$ for $3 \mathrm{~min}$. The supernatant was discarded, leaving only the sediment, which was then resuspended in added water, for a second round of centrifuging at $800 \times \mathrm{g}$. This procedure was repeated three times with water to clean the samples. The water was then removed and sodium nitrate (NaNO3) was added at a density of 1.30. This mixture was then resuspended and centrifuged again at $800 \mathrm{x} g$ for $3 \mathrm{~min}$. Finally, the tube was filled with sodium nitrate, thus forming a meniscus in the tube with a cover slip over it, and was incubated for $20 \mathrm{~min}$. Next, Toxocara spp. eggs were identified under the microscope, in accordance with the morphological descriptions of Bouchet [5].

The data were analyzed by means of Fisher's exact test in order to compare the presence of Toxocara eggs according to cat age and sex. The chi-square test was used to determine associations between variables and odds ratios (OR) were calculated to determine the risk factors that presented significance $(P<0.05)$. All the tests were conducted using the $\mathrm{JMP}^{\circledR} 8.0$ software $^{1}$.

\section{RESULTS}

The presence of Toxocara spp. eggs was identified in $42 \%(96 / 229)$ of the cats, of which $23 \%$ were males and $19 \%$ females. No significant difference between the sexes was found $(P=0.55)$, although the male cats showed a higher risk factor $(\mathrm{OR}=1.57)$ for the presence of Toxocara spp. eggs in feces.

According to the age classification, cats over one year old showed the largest percentage of positives (18\%); however, there was no statistically significant difference between the different age groups (Table 1). We did find an association between cats under the age of six months $(P=$ $0.01)$ and the presence of Toxocara spp. eggs, and therefore age was determined to be a risk factor $(\mathrm{OR}=1.69)$ for the presence of Toxocara spp. eggs in feces (Table 2). Cats over one year old showed a statistically significant association $(P=0.02)$ with the presence of parasite eggs in feces. In comparing age groups within each sex, there was no statistically significant difference with regard to different male age groups $(P=0.12)$; however, a statistically significant difference $(P=0.03)$ was found regarding the female group under six months of age (Table 3 ). Meanwhile, comparing positive cats of both sexes with age, a statistically significant difference $(P=0.02)$ was found regarding cats over one year old (Table 4$)$. 
Table 1. Differences between positive and negative cats of different ages with regard to Toxocara spp. eggs in feces.

\begin{tabular}{ccccc}
\hline Age & Positive & Negative & Total & $P$ \\
\hline$<=96(\%)$ & $\mathrm{n}=133(\%)$ & $34(15 \%)$ & 73 & 0.08 \\
6 6 months & $39(17 \%)$ & $21(9 \%)$ & 36 & 0.97 \\
$>$ 1 year & $15(7 \%)$ & $78(34 \%)$ & 120 & 0.20 \\
Total & $42(18 \%)$ & $133(58 \%)$ & 229 & \\
\hline
\end{tabular}

*Fisher exact test, significance $P<0.05$; no differences were found between groups.

Table 2. Association between age risk factors and Toxocara spp. egg presence in domestic cats in the state of Mexico.

\begin{tabular}{cccccccc}
\hline Age & $\begin{array}{c}\text { Positive } \\
\mathrm{N}=96\end{array}$ & $\begin{array}{c}\text { Negative } \\
\mathrm{N}=133\end{array}$ & $X^{2}$ & $P$ & OR & $P$ & CI \\
\hline$<6$ months & 39 & 34 & 5.82 & 0.01 & 1.69 & 0.06 & $0.973-2.951$ \\
$>$ 1 year & 42 & 78 & 4.96 & 0.02 & 0.54 & 0.02 & $0.322-0.932$ \\
\hline$\chi^{2}=$ Chi-square: association level, $P<0.05$ significance; OR $=$ Odds Ratio: risk factor; $P<0.05$ significance; CI $=$ confidence interval.
\end{tabular}

$\chi^{2}=$ Chi-square: association level, $P<0.05$ significance; $\mathrm{OR}=$ Odds Ratio: risk factor; $P<0.05$ significance; $\mathrm{CI}=$ confidence interval.

Table 3. Comparison of positive and negative cats of the same sex in relation to Toxocara spp. egg presence.

\begin{tabular}{ccccccc}
\hline Age & Positive males & Negative males & $P$ & Positive females & Negative females & $P$ \\
\hline$<6$ months & $20(9 \%)$ & $15(6 \%)$ & 0.12 & $20(8 \%)$ & $21(8 \%)$ & 0.03 \\
6 months to 1 year & $7(3 \%)$ & $10(4 \%)$ & 0.37 & $12(3 \%)$ & $24(5 \%)$ & 0.68 \\
\multicolumn{1}{c}{ 1 year } & $25(11 \%)$ & $32(14 \%)$ & 0.25 & $12(7 \%)$ & $31(20 \%)$ & 0.09 \\
\hline
\end{tabular}

Fisher exact test, significance $P<0.05$; negative females were different from the other groups.

Table 4. Evaluation of the differences between positive cats of different sexes and Toxocara spp. eggs in feces.

\begin{tabular}{cccc}
\hline Age & Positive males & Negative females & $P$ \\
\hline$<6$ months & $20(9 \%)$ & $20(8 \%)$ & 0.31 \\
6 months -1 year & $7(3 \%)$ & $12(3 \%)$ & 0.07 \\
$>$ 1 year & $25(11 \%)$ & $12(7 \%)$ & 0.02 \\
\hline
\end{tabular}

Fisher exact test, significance $P<0.05$; group over 1 year was different.

\section{DISCUSSION}

In the present study, were identified Toxocara spp. eggs in $42 \%$ of the feces of domestic cats from the state of Mexico. These results are similar to those reported by Martínez [17] in Mexico City, who found that $42.5 \%$ of cats were infected. They also reported that there was a larger number of infected cats under one year of age and that males had higher infection rates.

For both sexes, an age of less than six months was considered to be a risk factor for Toxocara infection. Although parasite presence was only found in female cats less than six months old, Shabbir [26] also found a higher likelihood of infection among cats under six months of age, compared with other age groups. This was probably due to the Toxocara life cycle, since the infection might start during lactation [16]. Kittens start to excrete eggs from the third week after birth onwards and the rates of excretion increase around the eighth week [4]. During the first months of life, the larvae migrate and finish their cycle, but when the cat has reached its mature stage, the larvae may become entrenched and avoid finishing their life cycle [9].

Male sex was identified as a risk factor for the presence of Toxocara spp. These results match the findings reported in the literature regarding sex [24,25]. 
There are studies that have shown that behavior such as roaming, burial of feces, marking of territory and hunting arguably make males more susceptible to parasites that are present in their prey $[1,8]$.

Toxocara spp. are distributed worldwide. For instance, in Italy, $58.3 \%$ of the cats studied were infected with $T$. cati [21]; in Iran, 54.5\% [24]; in Nigeria, $48.5 \%$ [28], and in Colombia, $43 \%$ [11]. These results are comparable to our findings and reflect the climatic adaptability of Toxocara spp. Moreover, this is one of the most common nematodes found in felines, and it is zoonotic. Nevertheless, T. cati is considered to have lower epidemiological potential than $T$. canis. On the other hand, low prevalence has also been reported; for instance, only $7.8 \%$ of the cats were infected with Toxocara spp. in a study in Canada [13].

In the present study, the Toxocara species was not identified because, morphologically, the eggs are very similar among species; differentiation is complicated and has poor accuracy [30]. In contrast, Cardillo [7] reported finding eggs of different species and sexes. They found Toxocara cati in $25 \%$ of the cats, Toxoscara leonina in $16.6 \%$ and both species in $20 \%$. Sommerfelt
[27] also found $T$. cati in $61.2 \%$ of cat feces as well as Toxoscara leonina in $15.1 \%$ of fecal samples.

The prevalence of Toxocara spp. in domestic cats in the state of Mexico is high, and represents a potential risk of human toxocariasis. Nonetheless, there have been no studies on the seroprevalence of $T$. cati in humans, unlike $T$. canis, for which prevalence of $22 \%$ was recently reported in the state of Mexico. This was associated with ownership of pets such as dogs and cats [23].

\section{CONCLUSION}

It is important reflect on the role of domestic cats as a source of infection and dissemination of parasites, including Toxocara spp., which can affect humans and other animals. Simultaneously, it is vital to generate comprehensive programs to control cat populations and the transmission of their diseases to humans.

\section{MANUFACTURERS}

${ }^{1}$ SAS Institute Inc. Cary, NC, USA.

Declaration of interest. The authors report no conflicts of interest. The authors alone are responsible for the content and writing of the paper.

\section{REFERENCES}

1 Afonso E., Lemoine M., Poulle M., Ravat M., Romand S., Thulliez P., Villena I., Aubert D., Rabilloud M., Riche B. \& Gilot F. 2008. Spatial distribution of soil contamination by Toxoplasma gondii in relation to cat defecation behaviour in an urban area. International Journal of Parasitology. 3(8-9): 1017-1023.

2 Archelli S. \& Kozubsky L. 2008. Toxocara and Toxocariosis. Acta Bioquímica Clínica Latinoamericana. 4(23): 379384.

3 Bahrami A., Doosti A., Nahravanian H., Noorian A. \& Ahmadi S. 2011. Epidemiological survey of gastro-intestinal parasites in stray dogs and cats. Australian Journal Basic Applied Sciences. 9(5): 1944-1948.

4 Barutzki D. \& Schaper R. 2013. Age-dependant prevalence of endoparasites in young dogs and cats up to one year of age. Parasitology Research. 112(1): 119-131.

5 Bouchet F., Araújo A., Harter S., Chaves S., Duarte A., Monnier J. \& Ferreira L. 2003. Toxocara canis (Werner, 1782) eggs in the pleistocene site of Menez-Dregan, France (300,000-500,000 years before present). Memorias do Instituto Oswaldo Cruz. 98(1): 137-139.

6 Chen J., Zhou D., Nisbet A., Xu M., Huang S., Li M., Wang C. \& Zhu X. 2012. Advances in molecular identification, taxonomy, genetic variation and diagnosis of Toxocara spp. Infection, Genetics and Evolution. 12(7): 1344-1348.

7 Cardillo N., Rosa A. \& Sommerfelt I. 2008. Preliminary study on the different stages of Toxocara cati in cats. Parasitología Latinoamericana. 63(1): 72-75.

8 Daprato B., Cardillo N., Kunic M., Berra Y. \& Sommerfelt I. 2011. Persistent environmental contamination by Toxocara cati in a public space. Revista Sapuvet de Salud Pública. 2(25): 25-35.

9 Despommier D. 2003. Toxocariasis: Clinical aspects, epidemiology, medical ecology and molecular aspects. Clinical Microbiology and Infection. 16(2): 265-272.

10 Durant J., Irenge L., Fogt W., Dumont C., Doucet J., Mignon B., Losson B. \& Gala J. 2012. Duplex quantitative real-time PCR assay for the detection and discrimination of the eggs of Toxocara canis and Toxocara cati (Nematoda, Ascaridoidea) in soil and fecal samples. Parasites and Vectors. 5(288): 1-9. 
11 Echeverry D., Giraldo M. \& Castaño J. 2012. Prevalence of intestinal helminths in cats in Quindío, Colombia. Biomédica. 32(3): 430-436.

12 Gómez F., Atehortua H. \& Orozco P. 2007. The influence of pets in human life. Revista Colombiana de Ciencias Pecuarias. 20(3): 377-383.

13 Hoopes J., Polley L., Wagner B. \& Jenkins E. 2013. A retrospective investigation of feline gastrointestinal parasites in western Canada. The Canadian Veterinary Journal. 4(4): 359-362.

14 Khademvatan S., Rahim F., Tavalla M., Abdizadeh R. \& Hashemitabar M. 2013. PCR-based molecular characterization of Toxocara spp. using feces of stray cats: a study from Southwest Iran. PLOS ONE. 6(3): 8.

15 Li M., Lin R., Chen H., Sani R., Song H. \& Zhu X. 2007. PCR tools for the verification of the specific identity of ascaridoid nematodes from dogs and cats. Molecular and Cellular Probes. 21(5-6): 349-354.

16 Magnaval J., Glickman L., Dorchies P. \& Morassin B. 2001. Highlights of human toxocariasis. Korean Journal of Parasitology. 39(1): 1-11.

17 Martínez B., Vázquez T., Romero N., Gutiérrez C. \& Amancio C. 2003. The prevalence of Toxocara cati in domestic cats in México City. Veterinary Parasitology. 114(1): 43-49.

18 Mcconnell A. 2011. The multiple self-aspects framework: self-concept representation and its implications. Personality and Social Psychology Review. 5(1): 3-27.

19 Mircean V., Titilincu A. \& Vasile C. 2010. Prevalence of endoparasites in household cat (Felis catus) populations from Transylvania (Romania) and association with risk factors. Veterinary Parasitology. 171(1-2): 163-166.

20 Mizgajska W. 2005. Recommended method for recovery of Toxocara and other geohelminth eggs from soil. Wiadomości parazytologiczne. 51(1): 21-22.

21 Mugnaini L., Papini R., Gorini G., Passantino A., Merildi V. \& Mancianti F. 2012. Pattern and predictive factors of endoparasitism in cats in Central Italy. Revue de Médecine Véterinaire. 163(2): 89-94.

22 Okulewicz A., Matysiak P., Buńkowska K. \& Hildebrand J. 2012. Toxocara canis, Toxocara cati and Toxascaris leonina in wild and domestic carnivores. Journal of Helminthology. 49(1): 3-10.

23 Romero N., Mendoza M., Yañez A., Ponce M., Bustamante M. \& Ramirez D. 2013. Prevalence and risk factors associated with Toxocara canis infection in children. The Scientific World Journal. 2013(1): 572-589.

24 Sadjjadi S., Oryan A., Jalai A. \& Mehrabani D. 2001. Prevalence and intensity of infestation with Toxocara cati in stray cats in Shiraz, Iran. Veterinarski Archiv. 71(1): 149-157.

25 Samuyus N., Made D. \& Ida B. 2013. Prevalensi Infeksi Cacing Toxocara cati pada Kucing Lokal di Wilayah Denpasar. Indonesia Medicus Veterinus. 2(4): 428-436.

26 Shabbir Z., Tabbani M., Tahir Y., Ahmad A., Rehaman Z. \& Umair S. 2010. Comparative clinical epidemiology of toxocariosis in dogs and cats. Pakistan Journal Zoology. 42(2): 129-133.

27 Sommerfelt I., Cardillo N., López C., Ribicich M., Gallo C. \& Franco A. 2006. Prevalence of Toxocara cati and other parasites in cats' faeces collected from the open spaces of public institutions: Buenos Aires, Argentina. Veterinary Parasitology. 140(3-4): 296-301.

28 Sowemimo 0. 2012. Prevalence and intensity of gastrointestinal parasites of domestic cats in Ode-Irele and Oyo communities, southwest Nigeria. Journal of Parasitology and Vector Biology. 4(1): 7-13.

29 Taranto J., Passamonte L., Marinconz R., Marzi C., Cajal P. \& Malchiodi L. 2000. Zoonotic parasitosis transmitted by dogs in the Chaco Salta. Medicina (Buenos Aires). 60(2): 217-220.

30 Uga S., Matsuo J., Kimura D., Rai S., Koshino Y. \& Igarashi K. 2000. Differentiation of Toxocara canis and Toxocara cati eggs by light and scanning electron microscopy. Veterinary Parasitology. 92(4): 287-294.

31 Zhu X., Jacobs D., Chilton N., Sani R., Cheng N. \& Gasser R. 1998. Molecular characterization of a Toxocara variant from cats in Kuala Lumpur, Malaysia. Parasitology. 117(2): 155-164. 